American Journal of Applied Sciences 6 (1): 152-156, 2009

ISSN 1546-9239

(C) 2009 Science Publications

\title{
Mass Structure Deformation Monitoring using Low Cost Differential Global Positioning System Device
}

\author{
Ramin S. Azar and Helmi Z.M. Shafri \\ Geomatics Engineering Unit, Department of Civil Engineering, Faculty of Engineering, \\ Universiti Putra Malaysia (UPM), 43400, Serdang, Selangor, Malaysia
}

\begin{abstract}
In this study, a technique for monitoring bridge deformation with the simplest GPS device available was demonstrated. The accuracy of these observations was evaluated and the best approach for this purpose was suggested. The device used was the low cost GS20 Leica single frequency GPS, which is a basic GPS receiver for this study. This study was done during March, April and May 2008. Five points were selected along Putrajaya Seri Wawasan cable bridge, two on ends and three along the slope and one point as base station established outside bridge area on stable ground. Three observations epochs per point were conducted to assess the bridge's stability. Virtual Rinex data were used for correcting base station observation. Results have shown that for limited usage and academic studies, these devices should be adequate. Switching to more precise requirements will need more investment on equipment.
\end{abstract}

Key words: GPS, DGPS, structure monitoring, bridge, deformation, movement

\section{INTRODUCTION}

Monitoring of engineering structures has become of importance particularly after the possibility of destructive natural catastrophes has increased. To this end, big engineering structures like suspension bridges, viaducts, tunnels and high buildings etc have been subjected to continuous monitoring surveys ${ }^{[1]}$. The technological developments in high precision point positioning systems together with no-human data transmission techniques without any atmospheric obligation have led to easy adaption of such monitoring systems for the objects in question ${ }^{[1]}$. With the development of Global Positioning System (GPS), the sampling frequency of GPS receiver can reach about 20 times per second, while the location precision can approach 5 10 $\mathrm{mm}$. So, GPS can be used in the displacement monitoring of large structures ${ }^{[5]}$.

The carrier phase double difference mathematic model can be adopted to survey the structures with GPS. This model can remove the error between the clocks in the satellite and the receiver. Because the errors of orbit and atmosphere are connected with the distance between the datum point and monitoring point, a GPS receiver antenna should be placed near to the target bridge as a reference station. This point should be stable, and there are no buildings above $5^{\circ}$ to envelop or reflect signals. Another GPS receiver antenna should be placed on the monitoring point, which is often at the mid-span, quarter span or the top of towers and there had better be no structures to envelop the signal, either. At least 5 satellites signal should be received at the same time, and the data will be stored in the computer. When the data is processed, the displacement of each time point can be obtained ${ }^{[5]}$. The results are provided in WGS 84 geodetic coordination. (The horizontal and vertical displacement of bridges can be computed by coordinate projection and translation). In DGPS positioning, we usually assume the position of the reference station is exactly known in WGS 84. In practice, however, the position of the reference station in WGS 84 may not be exactly known due to some practical difficulties. One situation is that there are no known points available in the positioning area and we have to use a point positioning method to determine the position of the reference station. Another case is that we have known points available in the working area but, the coordinates may not be in WGS 84 and we have to transfer the coordinates to WGS 84 . Therefore, it is of significance to investigate the effect of the reference station position errors on the remote station position. GPS monitoring of structures is just being recently adopted in Malaysian infrastructure industry and this study was conducted to evaluate the possibilities and limitations to run such tasks on different type structures in Malaysia. More work is being planned to expand

Corresponding Author: Ramin S. Azar, Geomatics Engineering Unit, Department of Civil Engineering, Faculty of Engineering, Universiti Putra Malaysia (UPM), 43400, Serdang, Selangor, Malaysia 
GPS monitoring on high rise buildings and towers in Malaysia. As a mid traffic bridge, Seri Wawasan bridge in Putrajaya was selected as study site to be monitored from March to May 2008. Limitations for using low cost GPS devices were assessed and suggestions were made. Although several methods such as RTK were available but here post processing was selected since the equipment were not able to receive real time signals. In this research we have chosen post-processing method with use of two Leica GS20 GPS system with the cost of about \$USD 13,000. This GPS system has an accuracy of about $1 \mathrm{~m}$ on the field and $10 \mathrm{~cm}$ after single frequency post-processing but when they are post processed in double frequency phase their accuracy will reach to $1 \mathrm{~cm}$, which is still not enough if we are doing very precise measurements such as static load. Since we are intended to achieve an experiment in using low cost GPS systems to monitor movements of bridge due to wind or traffic movement it would roughly show us if the bridge is stable or the variance of its movements is too high. If a static load analysis or high precision method were to be carried, it would be better always to use real-time method with real-time connection to correction station. The cost of these devices would then go up to three or four times more ${ }^{[3,4]}$. Another way would be to establish two reference stations, which also increases the number of devices needed.

\section{MATERIALS AND METHODS}

In this project we have selected Seri Wawasan mid-traffic bridge, $3 \mathrm{~km}$ from Kampong Simpang Empat, located in Putrajaya, Selangor, Malaysia. Its structure was built with steel cables and its pylon was built with reinforced concrete (Fig. 1). The main span is $168.5 \mathrm{~m}$, the total length is $240 \mathrm{~m}$, it has 102 cables, the deck width is $37.2 \mathrm{~m}$ and the pylon height is $85 \mathrm{~m}$. 250 $\mathrm{t}$ of pre-stressed steel has been used in this bridge. It has a very beautiful design that attracts many tourists.

This bridge is located in Persiaran Barat Street with the coordinates mentioned below:

Latitude: $\quad 2^{\circ} 55^{\prime} 43.29 ” \mathrm{~N}$

Longitude: $101^{\circ} 40 ' 56.81^{\prime \prime} \mathrm{E}$

Since our project is to evaluate the possibility and the accuracy of using low-cost GPS equipments in order to monitor deformation or the movements of the bridge, we used the Leica GS20 GPS system, which costs about RM 40,000 (Fig. 2). This GPS has LEIAT501 series Leica antenna. The software provided with this GPS is Leica DataPro, but since this software processes single frequency data (L1) we had to switch to Leica GeoOffice software.

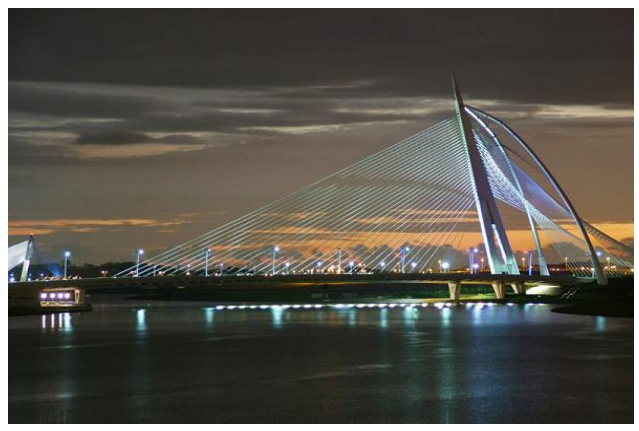

Fig. 1: Persiaran Barat, cable-bridge

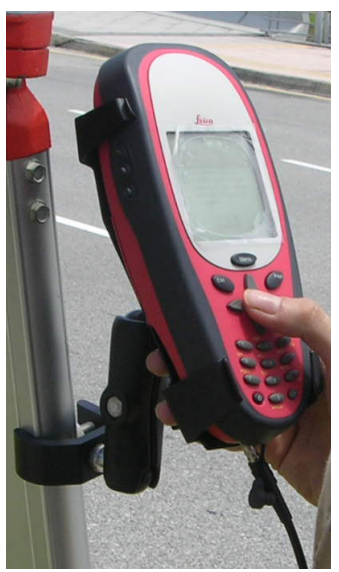

Fig. 2: Leica GS20

This device has an accuracy of about $1 \mathrm{~m}$ but when we process it by Leica GeoOffice software, the accuracy reaches $1 \mathrm{~cm}$ which would be fairly enough for us to evaluate the deformation of the bridge. Since we are not monitoring the real time movements of the bridge, this accuracy can tell us if any damaging movements have occurred to the bridge or not.

In case that we need more accuracy for movement monitoring, we have to go for much more expensive devices and more capable antennas ${ }^{[2]}$.

The method used for this project is based on Differential GPS (DGPS), which is correcting a station using one or two reference stations. In our case one base station is considered out of bridge area on stable ground in a position that no buildings have surrounded it, in order to reduce multipath effect ${ }^{[6]}$.

Five observation stations were considered along the bridge in a way that the middle one is located right at the highest elevation of the road (Fig. 3).

Distances between stations are as follow:

From Base to Rover 1: $17 \mathrm{~m}$, From Rover1 to Rover2: $47.5 \mathrm{~m}$ 
Am. J. Applied Sci., 6 (1): 152-156, 2009

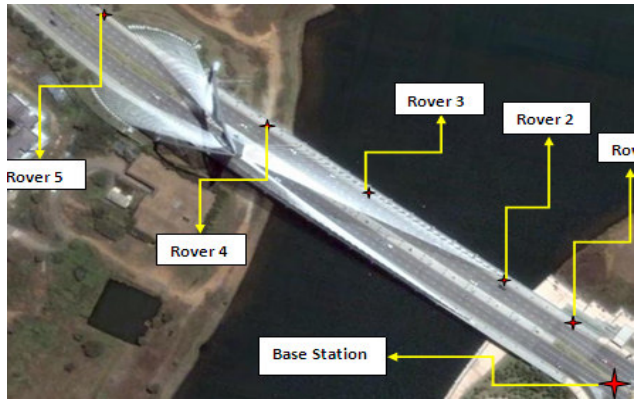

Fig. 3: Observation stations

From Base to Rover 2: $55 \mathrm{~m}$

From Rover2 to Rover3: $84.5 \mathrm{~m}$

From Base to Rover 3: $136 \mathrm{~m}$

From Rover3 to Rover4: $73.5 \mathrm{~m}$

From Base to Rover 4: $228 \mathrm{~m}$

From Rover4 to Rover5: $70.5 \mathrm{~m}$

From Base to Rover 5: 296 m

Two devices are needed, one for the base station and one for rover observation ${ }^{[7,8]}$. The base station is installed on a tripod and the rover moves on a pole, which is fixed carefully on each point. The base station starts observing from the beginning of the task till one round is finished; five rover stations in this case. Each GPS device has a limitation of nods for one observation, each round must be finished before this time exceeds.

Every rover station observes for $10 \mathrm{~min}$, when this period is finished we roll to the next point. This gets us $50 \mathrm{~min}$ for all points together and $20 \mathrm{~min}$ extra for displacing and re-establishing the new station. Note that every epoch of observation is saved as a different job in GPS device and they will be loaded separately in Geooffice software. Each epoch is corrected with relevant base station and all base stations are corrected with virtual rinex data.

Stations are marked exactly for the next round to go. Second and third observations will be done with the same details. The more epochs of observation will bring better results to compare. GPS device must be set up carefully in order to give the appropriate data. Antenna settings must be checked and log on static mode must be turned on in tracking settings of the GPS device. The height of the antenna is also given to the GPS, which are $2 \mathrm{~m}$ both for our rover and base.

For each round one new base station is considered to cover all range of rover observations. All base stations will be corrected using Virtual Rinex data and then Rover stations will be corrected using Base stations.
Every country has a network of CORS points generated by their surveying organization, in our case by the Department of Surveying and Mapping, Malaysia (JUPEM). These points are observed and corrected formerly by the most exact corrections possible to be done but, this network of points is not so dense to cover all tasks and since we are going for an accurate measurement, we need much more precise data than that. Here comes Virtual Rinex data that is a high cost selling data for surveying. Contrary to CORS points which are permanent and same all the time and they may be couple of kilometers far from observation site, Virtual Rinex data depends on the time and date of observation of the base station. The surveying organization generates a point based on the information given to them in someplace near our base station, nearly $2 \mathrm{~m}$. The interval considered for this survey is 1 second. Later, this point will help us to correct our base station depending on Virtual Rinex data.

First, each base station is corrected using Virtual Rinex data for that specific time in Geooffice software. This corrects the base station using VR. Then each epoch of observation is corrected relative to its related base station. Note that the time of base station observation has to be more than rover observations if not the out region rover observations could not be corrected. When all the rover observations are corrected the data would be compared depending on each epoch of observation. But there is a slight problem. GPS coordinates are in WGS84 format, which is global degree format. For comparison they were converted into meter format in RSO using ILWIS software.

For this matter we need to establish main points for bridge area.

Our main points are as the following: Main points:

Min (x): $797936.38 \mathrm{~m} \mathrm{E} \quad$ Min (y): $323698.59 \mathrm{~m} \mathrm{~N}$ Max (x): $799060.31 \mathrm{~m} \mathrm{E} \quad$ Max (y): $324197.81 \mathrm{~m} \mathrm{~N}$

These main coordinates are given to ILWIS software as main points in order to generate a command box, which can transfer WGS84 coordinates to RSO. The projection is selected as UTM, ellipsoid as Everest Malaysia 1969 and datum as Kertau 1984; note that north hemisphere should be checked and Malaysia zone is 47. Then we enter our coordinates and the RSO format will be given and we can compare the points.

\section{RESULT AND DISCUSSION}

The results show there is no deformation more than $1 \mathrm{~cm}$ in our stations, however there is a slight difference 
Am. J. Applied Sci., 6 (1): 152-156, 2009

Table 1: GPS monitoring results

\begin{tabular}{|c|c|c|c|c|}
\hline \multicolumn{2}{|c|}{ Station } & \multicolumn{3}{|l|}{ Rover No. } \\
\hline \multirow[t]{8}{*}{1} & WGS84 & POINT00001 & POINT00006 & POINT00011 \\
\hline & & $2^{\circ} 55^{\prime}$ & $2^{\circ} 55^{\prime}$ & $2^{\circ} 55^{\prime}$ \\
\hline & & $40.01131 " \mathrm{~N}$ & $40.01135 " \mathrm{~N}$ & $40.01100 " \mathrm{~N}$ \\
\hline & & $101^{\circ} 41^{\prime}$ & $101^{\circ} 41^{\prime}$ & $101^{\circ} 41^{\prime}$ \\
\hline & & 06.70833" E & $06.70865 " \mathrm{E}$ & 06.70815" E \\
\hline & RSO & POINT00001 & POINT00006 & POINT00011 \\
\hline & & 798639.84 & 798639.84 & 798639.84 \\
\hline & & 323963.57 & 323963.57 & 323963.57 \\
\hline \multirow[t]{8}{*}{2} & WGS84 & POINT00002 & POINT00007 & POINT00012 \\
\hline & & $2^{\circ} 55^{\prime}$ & $2^{\circ} 55^{\prime}$ & $2^{\circ} 55^{\prime}$ \\
\hline & & $40.57617 " \mathrm{~N}$ & $40.57601 " \mathrm{~N}$ & $40.57650 " \mathrm{~N}$ \\
\hline & & $101^{\circ} 41^{\prime}$ & $101^{\circ} 41^{\prime}$ & $101^{\circ} 41^{\prime}$ \\
\hline & & $05.34890 " \mathrm{E}$ & $05.34821 " \mathrm{E}$ & $05.34920 " \mathrm{E}$ \\
\hline & RSO & POINT00002 & POINT00007 & POINT00012 \\
\hline & & 798597.79 & 79859 & 798597.79 \\
\hline & & 323980.83 & 323980.83 & 323980.83 \\
\hline \multirow[t]{8}{*}{3} & WGS84 & POINT00003 & POINT00008 & POINT00013 \\
\hline & & $2^{\circ} 55^{\prime}$ & $2^{\circ} 55^{\prime}$ & $2^{\circ} 55^{\prime}$ \\
\hline & & $41.74767 " \mathrm{~N}$ & $41.74789 " \mathrm{~N}$ & $41.74720 " \mathrm{~N}$ \\
\hline & & $101^{\circ} 41^{\prime}$ & $101^{\circ} 41^{\prime}$ & $101^{\circ} 41^{\prime}$ \\
\hline & & $02.59858 " \mathrm{E}$ & 02.59890" E & 02.59812" E \\
\hline & RSO & POINT00003 & POINT00008 & POINT00013 \\
\hline & & 798512.70 & 798512.70 & 798512.70 \\
\hline & & 324016.63 & 324016.63 & 324016.63 \\
\hline \multirow[t]{8}{*}{4} & WGS84 & POINT00004 & POINT00009 & POINT00014 \\
\hline & & $2^{\circ} 55^{\prime}$ & $2^{\circ} 55^{\prime}$ & $2^{\circ} 55^{\prime}$ \\
\hline & & $42.80767 " \mathrm{~N}$ & 42.80744" N & $42.80750 " \mathrm{~N}$ \\
\hline & & $101^{\circ} 41^{\prime}$ & $101^{\circ} 41^{\prime}$ & $101^{\circ} 41^{\prime}$ \\
\hline & & $00.13198 " \mathrm{E}$ & $00.13129 " \mathrm{E}$ & 00.13145" E \\
\hline & RSO & POINT00004 & POINT00009 & POINT00014 \\
\hline & & 798436.38 & 798436.38 & 798436.38 \\
\hline & & 324049.03 & 324049.03 & 324049.03 \\
\hline \multirow[t]{8}{*}{5} & WGS84 & POINT00005 & POINT00010 & POINT00015 \\
\hline & & $2^{\circ} 55^{\prime}$ & $2^{\circ} 55^{\prime}$ & $2^{\circ} 55^{\prime}$ \\
\hline & & $43.63265 " \mathrm{~N}$ & 43.63243" N & $43.63212 " \mathrm{~N}$ \\
\hline & & $101^{\circ} 40^{\prime}$ & $101^{\circ} 40^{\prime}$ & $101^{\circ} 40^{\prime}$ \\
\hline & & $58.31698 " \mathrm{E}$ & 58.31646" E & 58.31593" E \\
\hline & RSO & POINT00005 & POINT00010 & POINT00015 \\
\hline & & 798380.23 & 798380.23 & 798380.23 \\
\hline & & 324074.25 & 324074.25 & 324074.25 \\
\hline
\end{tabular}

in coordinates of the points which is not due to movement but the error of device or any other possible causes.

This indicates that the bridge has been stable practically during period of observation and there is no need to take a conservative action about it since the safety factor has not been passed.

For monitoring very accurate deformations such as dam deformation or high rise deformation monitoring, it would be suggested to use accurate and high cost GPS devices which can determine movements about 5 $\mathrm{mm}$. Although it is costly but considering the importance of the project this would derive more benefits.

For the monitoring of real time movements of structures such as bridge under pressure of static load or wind force, it would be suggested to use RTK-Net and real time processing which gives the on going and real time movements of structure for every fraction of seconds depending on the device. However, for lowering the cost of survey, practically hand held GPS devices can be used with several extra software operations with acceptable results ${ }^{[3,4]}$.

The results obtained in this study are presented in Table 1.

\section{CONCLUSION}

Low cost GPS for monitoring deformation of Seri Wawasan bridge in Putrajaya had been tested using GS20 Leica single frequency GPS. Five points were marked and three rounds of observation in different days were done. Results were analyzed with Leica GeoOffice and ILWIS software and no noticeable deformation was witnessed. Stability of the points was proven or at least there is no deformation more than $1 \mathrm{~cm}$. The results seem to be acceptable but for more precise results and more accurate deformation monitoring it is suggested to use high accuracy GPS devices and double frequency antennas.

\section{REFERENCES}

1. Akyılmaz, O., A. Çelik, A. Apaydın and T. Ayan, 2005. GPS Monitoring of the Fatih Sultan Mehmet Suspension Bridge By using Assessment Methods of Neural Networks. The International Archives of the Photogrammetry. Remote Sensing and Spatial Information Sciences. 34: Part 30. http://www.isprs.org/istanbul2004/comm7/papers/1 $\underline{38 . p d f}$

2. Baraka, M.A. and A.H. El-Shazly, 2005. Monitoring Bridge Deformations during Static Loading Tests Using GPS. Deformation Measurement and Analysis. Cairo, Egypt. http://www.fig.net/pub/cairo/papers/ts_43/ts43_04 baraka_elshazly.pdf

3. Cosser, E., J.C. Hill, G.W. Roberts, X. Meng, T. Moore and H.A. Dodson, 2004. Bridge monitoring with garmin handheld receivers. 1st FIG International Symposium on Engineering Surveys for Construction Works and Structural Engineering. Nottingham, United Kingdom. http://www.fig.net/nottingham/proc/gs_05_cosser_ etal.pdf

4. Cosser, E., G.W. Roberts, X. Meng and A.H. Dodson 2004. Single frequency GPS for bridge deflection monitoring: Progress and results. 1st FIG. International Symposium on Engineering Surveys for Construction Works and Structural Engineering. United Kingdom. http://www.fig.net/ nottingham/proc/ts_04_3_cosser_etal.pdf 
5. Jianjing, J., L. Xinzheng and G. Jingjun, 2002. Study for Real-time Monitoring of Large-Span Bridge Using GPS. Progress in Safety Science and Technology. Science Press. Beijing New York. pp: 308-312. http://www.luxinzheng.net/ publications/11.htm

6. Raziq, N. and P. Collier, 2006. High Precision GPS Deformation Monitoring using Single Receiver Carrier Phase Data. Geodetic Deformation Monitoring: From Geophysical to Engineering Roles. Springer Berlin Heidelberg Publishing. 131: 95-102. http://www.springerlink.com/index/t 01218k35428w233.pdf
7. Roberts, G.W., E. Cosser, X. Meng and A. Dodson, 2004. High frequency deflection monitoring of bridges by GPS. J. Global Positioning Sys., 3: 226-231. http://www.gmat.unsw.edu.au/wang/ jgps/v3n12/v3n12p28.pdf

8. Vermeer, M., 2002. Review of the GPS deformation monitoring studies commissioned by Posiva Oyon the Olkiluoto, Kivetty and Romuvaara sites, 1994-2000. STUK-YTO-TR 186. Helsinki Pp: 1-21. http://www.stuk.fi/julkaisut/ tr/stuk-yto-tr186.pdf 